\title{
Die jüdischen Feste im Bellum Judaicum des Flavius Josephus
}

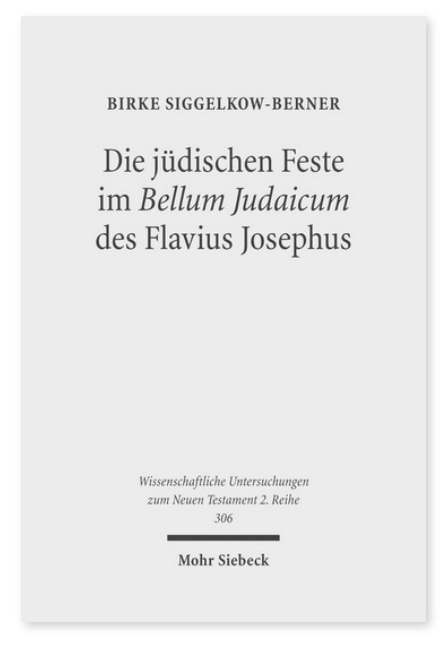

2011. XIII, 441 Seiten. WUNT II 306

ISBN 978-3-16-151649-8

DOI 10.1628/978-3-16-151649-8

eBook PDF 114,00€

ISBN 978-3-16-150593-5

fadengeheftete Broschur 114,00€
Flavius Josephus gilt als einer der wichtigsten Zeugen für Praxis und Deutung der jüdischen Feste in der Zeit vor 70 n.Chr. Jedoch stand bisher eine Untersuchung aus, die die entsprechenden Belegstellen in ihrem literarischen Kontext wahrnimmt. Birke Siggelkow-Berner greift den Befund auf, dass die jüdischen Feste im Bellum Judaicum eigens als Thema genannt werden sowie sprachlich und sachlich als ein klar abgegrenzter Komplex erscheinen. Sie analysiert alle Festbezüge in dieser Schrift auf ihre Kontexteinbindung hin und kommt zum Ergebnis, dass diese Textpassagen gezielt für den Geschichtsbericht im Kontext gestaltet sind. Josephus nutzt das Deutungspotential der Feste in ihrem Bezug auf das ganze Volk, auf Jerusalem und auf den Tempel und nimmt auf diese Weise eine Verhältnisbestimmung zwischen dem Judentum und Rom sowie zwischen den jeweiligen Protagonisten vor, die auch heilsgeschichtliche Implikationen hat. Damit unterstützen und vertiefen die Festbezüge die Aussageintention des Bellum Judaicum insgesamt.

Birke Siggelkow-Berner Geboren 1977; Studium der Theologie in Göttingen; 2009 Promotion; seit 2009 Vikarin der Evangelisch-lutherischen Landeskirche Hannovers in Obernjesa.

Jetzt bestellen:

https://mohrsiebeck.com/buch/die-juedischen-feste-im-bellum-judaicum-des-flavius-josephus-9783161516498?no_cache=1 order@mohrsiebeck.com

Telefon: +49 (0)7071-923-17

Telefax: $+49(0) 7071-51104$ 